\title{
Significant intimal abnormalities in muscular pulmonary arteries of patients with early obstructive lung disease
}

\author{
JUNE M FERNIE,* A MCLEAN, D LAMB \\ From the *Institute of Occupational Medicine, Edinburgh, and the Department of Pathology, University of \\ Edinburgh Medical School, Scotland
}

SUMMARY Substantial intimal changes, unrelated to aging, were found in resected lobes or lungs of 30 smokers with early obstructive lung disease (22 men, eight women: age range 46-74 years: forced expiratory volume in one second $\left(\mathrm{FEV}_{1}\right) \%$ predicted range $\left.47-119 \%\right)$. Intimal area was measured using a digitiser and expressed as a proportion of the area enclosed by the internal elastic lamina (IEL), correcting for constriction (intima index). Arteries were subdivided into four size (length IEL) groups. For the smallest group ( $\leqslant 600 \mu \mathrm{m}$ length IEL) the mean intima index (II600) ranged from $0 \cdot 09-0 \cdot 34$; half the values were $\geqslant 0 \cdot 20$. Intimal abnormality was unrelated to the size or site of tumour or to macroscopic emphysema, and correlated weakly with pack years. II600 values were, however, significantly correlated with factors known to be affected by smoking such as alveolar wall surface area per unit lung volume, $\mathrm{FEV}_{1} \%$ predicted, and $\mathrm{FEV}_{1} / \mathrm{FVC}$ (forced vital capacity); these last two factors were also significantly associated with intimal abnormality in arteries measuring 601$1200 \mu \mathrm{m}$ length IEL.

An increase in the intima of muscular pulmonary arteries may have functional implications for the pulmonary circulation in terms of flow and pressure changes..$^{1-3}$ As such there have been many studies of the intima both in normal and disease states. Those studying healthy subjects have commented that patchy intimal changes are a common and very variable feature of aging. ${ }^{47}$ The issue of whether smoking has an effect on the intima is still open to debate. Some workers have implicated smoking as a cause of increased intimal thickening in muscular pulmonary arteries. ${ }^{78}$ In a study of 23 subjects without evidence of any cardiopulomary disease likely to have affected the pulmonary vasculature, however, we could find no systematic differences in the intima between smokers and non-smokers. ${ }^{9}$ Although the extent of intimal abnormality is very variable in healthy subjects, it is generally acknowledged that clinically important widespread abnormality is normally found only in association with specific pathology. ${ }^{23}$

This paper describes the pronounced intimal abnormality observed in the resected lobes and lungs of $\mathbf{3 0}$ smokers with small peripheral lung carcinomas, and how this relates to structural and functional abnormalities within the lung.

Accepted for publication 18 February 1988

\section{Material and methods}

Between September 1980 and May 1984 material was obtained from resection operations carried out at the City Hospital, Edinburgh, on patients with suspected lung carcinomas. Thirty of these specimens were included in the present study; three were whole lungs and 27 were single lobes (18 upper, three middle, and six lower lobes).

The patients were predominantly male $(22 \mathrm{men}$, eight women ranging in age from 46 to 74 years; all were current $(n=26)$ or ex-smokers $(n=4)$. Data were available on amount smoked, years smoked, and years of not smoking (where relevant) and were used to calculate total pack years. In all cases the smoking histories were obtained directly from the patient using a standard questionnaire.

During the week before surgery, patients underwent a series of pulmonary function tests and measurements of blood gases. The data available included: forced expiratory volume in one second $\left(F E V_{1}\right)$, forced vital capacity (FVC), total lung volume (TLC), residual volume (RV), transfer factor (TCO), transfer factor per unit of lung volume (KCO), $\mathrm{PaO}_{2}$ and $\mathrm{PaCO}_{2}$. The FEV 1 and FVC measurements were additionally expressed as a percentage of predicted values for age and height for women ${ }^{10}$ and for men. ${ }^{11}$ 
PREPARATION OF SPECIMENS

After inflation with formol saline through the main or lobar bronchus fixation was allowed to continue for a minimum of 24 hours before cutting lungs or lobes into $1 \mathrm{~cm}$ sagittal slices. ${ }^{12}$ Twelve tissue blocks $(1.9 \times 1.9 \times 0.6 \mathrm{~cm})$ were then taken from the two most lateral slices. Areas containing carcinomas, which were generally small and peripherally situated, were avoided. The 12 blocks, which were selected from the remainder of these two slices, were selected using a random sampling technique. After embedding in glycol methacrylate the tissue blocks were sectioned at $3 \mu \mathrm{m}$ using the technique of $\mathrm{Sims}^{13}$ and stained for elastic. $^{14}$

\section{METHOD OF MEASUREMENT}

Cross sectionally cut muscular pulmonary arteries were assessed by measuring the area of the intima and relating this to artery size using total length of internal elastic lamina (IEL) as the criterion for artery size. All measurements were obtained using a semiautomatic digitising system; precise details of the measuring procedures followed have been reported previously. ${ }^{1516}$ An average of 57 muscular pulmonary arteries were measured in each subject.

\section{CALCULATION OF INTIMA INDICES}

Data on the intima of each measured artery were expressed in a way which reflected the true extent of lumen occlusion (the intima index). These intima indices were calculated by dividing the area of the intima by the area enclosed by the IEL in its theoretically uncollapsed/unconstricted state. ${ }^{9}$ This is necessary to accommodate differences in the degree of collapse or constriction between arteries, which can be very variable. Values for intima index range from $>0$ to $\leqslant 1$, indicating minimal through to total occlusion of the artery lumen by intimal change.

\section{ASSESSMENT OF EMPHYSEMA}

Emphysema was assessed macroscopically as a percentage of the area of the mid-sagittal lung or lobe slice. Types of emphysema were not considered separately.

Emphysema was also assessed microscopically by a method which assesses alveolar wall surface area per unit volume (AWUV as $\mathrm{mm}^{2} / \mathrm{mm}^{3}$ ) from measurements of alveolar perimeter per unit area on histological sections using an IBAS2 automatic analyser. Measurements were made on random fields (18-35) from each of the 12 tissue sections available from each subject. Perimeter measurements were converted to AWUV by the formula AWUV$=$ alveolar perimeter $\left.\left(\mathrm{mm} / \mathrm{mm}^{2}\right) \times 4 \div \pi .^{17}\right)$ In our study the AWUV value used to represent each subject was that of mean AWUV.
ANALYSIS OF DATA

The data on individual arteries together with those on smoking, respiratory function, blood gases and emphysema were transferred to tape on the mainframe computer (a PRIME 750) at the Institute of Occupational Medicine. All analyses were carried out using the statistical package "Minitab". ${ }^{18}$

\section{Results}

PRELIMINARY ANALYSIS OF INTIMA INDICES FOR INDIVIDUAL SUBJECTS

For all subjects the intima index was found to vary with artery size (total length of IEL), smaller arteries being proportionately more affected by intimal change (fig 1). To compare subjects it was therefore necessary to calculate mean intima indices for arteries subdivided into size groups. In previous studies ${ }^{9}$ the size groups chosen were: up to $600 \mu \mathrm{m}$ total length of IEL, $601-1200,1201-1800$, and $>1800 \mu \mathrm{m}$ total length of IEL. Analysis of the relation between intima index and artery size for all $\mathbf{3 0}$ subjects showed that these four size groups were also the most appropriate to use for the present study. The corresponding mean intima indices were termed II600, II1200, III800 and II $>1800$, the figures denoting the upper limit of the size range of arteries included in each group.

The range of the mean intima indices observed in the 30 resection specimens was as follows: II600 0.09-0.34; II $12000.06-0.24$; III $18000.03-0.13$; II > $18000.02-$ 0.07 .

RELATION BETWEEN INTIMAL ABNORMALITY AND THE STUDY VARIABLES

In the resection specimens intimal abnormality was not related to age-shown for the smallest size group of arteries (II600) in fig $2(r=0 \cdot 14)$. The value for the II600 ranged from $0.09-0.34$, and more than half of

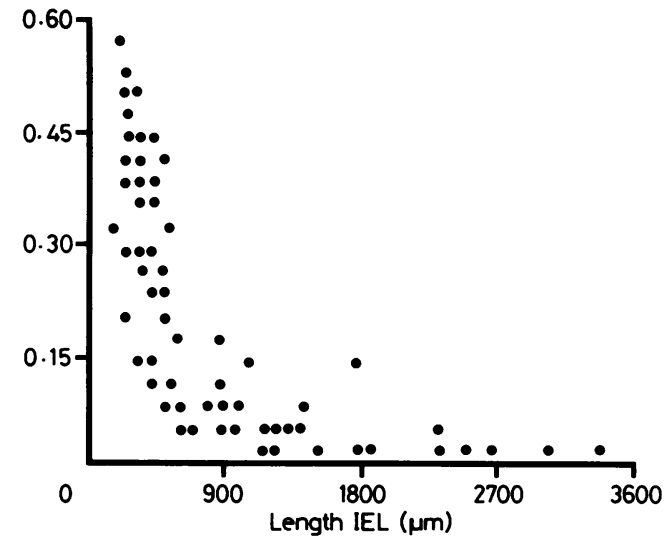

Fig 1 Relation between intima index and artery size for one subject. 


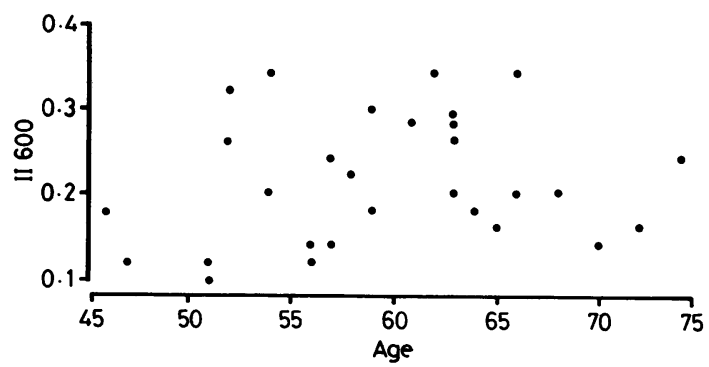

Fig 2 Relation between mean intima index of arteries in smallest size group (II600) and age.

the patients had values of 0.2 or greater-that is, greater than $20 \%$ lumen occlusion.

Although positive associations were observed between smoking (expressed as pack years) and intimal abnormality (expressed as mean intima indices), the associations were heavily influenced by a very small number of subjects with high values for pack years. The II600 result is illustrated in fig 3 .

In terms of structural changes within the lung there was no association between intimal abnormality and macroscopic emphysema, the incidence of which in the study group was low. A significant $(p<0.02)$ positive association, however, was observed between intimal abnormality and mean AWUV, specificantly for the smallest size group of arteries (fig 4). A low AWUV value indicates a loss of alveolar surface area-that is, microscopic emphysema. In the resection specimens low AWUVs tended to be found in association with high levels of intimal abnormality and vice versa.

Intimal abnormality was also significantly associated with functional as well as structural changes within the lung. Values for II600 (fig 5) and II1 200 were both significantly $(p<0.02)$ correlated with $\mathrm{FEV}_{1}$, expressed as a percentage of that predicted for age and height. Similar significant associations were observed between intimal abnormality (II600 and II1200) and FEV expressed as a percentage of FVC (results not shown). The $r$ values were -0.61 and -0.48 , respectively.

Intimal abnormality was unrelated to any of the other pulmonary function or blood gases data.

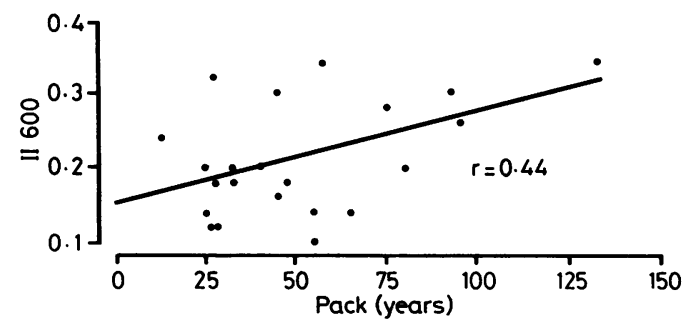

Fig 3 Relation between mean intima index of arteries in smallest size group (II600) and pack years.
Discussion

This study has shown that there is a significant level of intimal abnormality in a group of smokers, which is associated with some degree of structural and functional abnormality within the lung.

It is appropriate perhaps to begin a discussion of these findings with some comments on the material used in the study. Firstly, our material comprised a mixture of whole lungs and lobes and as such we were not comparing subjects on a strictly similar basis, but we felt that this was justifiable on the grounds that we have previously shown that intimal abnormality does not vary between lobes. ${ }^{9}$ Secondly, the subjects studied were a highly selected group in that they all had peripheral carcinomas and were considered to be fit for operation. This leads to one possible explanation for the pronounced intimal abnormality: it is somehow related to the presence of the carcinoma. Tissue blocks taken distal to the segment containing the carcinoma, however, showed no evidence of more severe intimal abnormality, and from this we concluded that the tumours were not having a local effect on the intima.

Other workers have studied pulmonary blood vessels in resection specimens. ${ }^{2021}$ Some concluded that the increased arterial intimal thickening was associated with smoking. ${ }^{21}$ The other group, who specifically studied the ultrastructure of the intimal fibrosis, believed the intimal fibrosis to be associated with aging rather than the bronchial neoplasm. ${ }^{20}$ Our results indicate that the intimal abnormality is unlikely to be simply a function of aging. First there was no direct relation between the level of intimal abnormality and patient age, which may be due to the fact that the study group was predominantly middle-aged and did not cover the extremes of age. A second factor which militates against aging being solely responsible is that the extent of intimal abnormality in the resection specimens was much higher than that observed in a previously studied group in whom we detected an age effect. ${ }^{9}$ That particular necropsy study

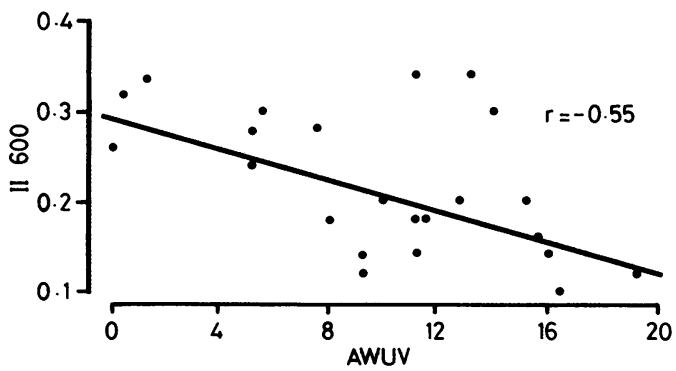

Fig 4 Relation between mean intima index of arteries in smallest size group (I1600) and microscopic emphysema ( $A W U V)$. 
Significant intimal abnormalities in lungs of smokers

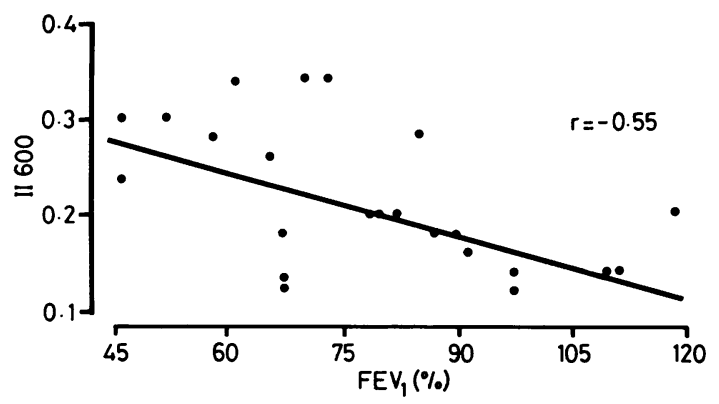

Fig 5 Relation between mean intima index of arteries in smallest size group (I1600) and FEV $V_{1}$ expressed as percentage of predicted value.

consisted of subjects showing no evidence of any cardiopulmonary disease likely to have affected the pulmonary vasculature. ${ }^{9}$ The differences between these two study groups are considerable and are quite specific to the intima. Taking the smallest size group of arteries as an example, only one of the 23 subjects in the group without any cardiopulmonary disease had an II600 value of $\geqslant 0 \cdot 2^{9}$ whereas more than half of the 30 subjects in the resection group did so.

We consider lumen occlusion in excess of $20 \%$ to be quite pronounced given that these values are minimum possible values because they were calculated independently of artery constriction or collapse to ensure comparability between subjects. If the degree of crenation observed in the internal elastic lamina does reflect the amount of tone in the arteries during life, and is not simply an artefact after death, then the degree of lumen occlusion by intimal abnormality is very much higher. To illustrate this, one of the patients in the resection group had a mean II600 of 0.32 after accounting for constriction or collapse-that is $32 \%$ lumen reduction in arteries measuring less than $600 \mu \mathrm{m}$ length of internal elastic lamina. If the constriction collapse had not been accounted for, the observed actual mean II600 would have been 0.72 or $72 \%$ lumen reduction. Such severe lumen reduction has obvious implications with respect to pulmonary vascular resistance.

The differences we have noted in intimal abnormality between the group without any cardiopulmonary disease ${ }^{9}$ and the resection group are probably related to smoking, either directly or indirectly, those in the resection group being, in general, much heavier smokers. We have shown that the level of intimal abnormality, particularly in the smaller arteries, is strongly correlated with both structural (reduced alveolar surface area per unit lung volume) and functional (reduced ventilatory capacity) abnormalities within the lung, both of which are known to be related to smoking. It may be that the resection group comprises patients with a particularly high response to smoking.

In general, the patients we studied had evidence of early obstructive lung disease. Given the nature of the study group, however, some of the patients will probably go on to develop more severe obstructive lung disease. Our results are interesting in that they indicated that pronounced vascular (intimal) changes occur relatively early in the natural history of chronic airflow obstruction. Although the precise functional importance of these vascular changes is not known, they may be important in the eventual development of pulmonary hypertension.

\section{References}

1 Harris P, Heath D. The human pulmonary circulation. Second Edition. Edinburgh: Churchill Livingstone, 1977.

2 Moser KM, ed. Pulmonary vascular diseases. New York: Marcel Dekker Inc., 1979.

3 Wagenvoort CA, Wagenvoort N. Pathology of pulmonary hypertension. New York: John Wiley \& Sons, 1977.

4 Brenner O. Pathology of the vessels of the pulmonary circulation. Part II. Secondary pulmonary vascular sclerosis. Arch Intern Med 1935;56:724-52.

5 Wagenvoort CA, Wagenvoort $\mathbf{N}$. Age changes in muscular pulmonary arteries. Archives of Pathology. 1965;79:524-28.

6 Warnock ML, Kunzmann A. Changes with age in muscular pulmonary arteries. Arch Pathol Lab Med 1977;101:175-9.

7 Hale KA, Niewoehner DE, Cosio MG. Morphologic changes in the muscular pulmonary arteries. Relationship to smoking, airway disease, and emphysema. Am Rev Respir Dis 1980; 122:273-8.

8 Auerbach O, Short AP, Hammond EC, Garfinkel L. Smoking habits and age in relation to pulmonary changes. Rupture of alveolar septums, fibrosis and thickening of small arteries and arterioles. N Engl J Med 1963;269:1045-54.

9 Fernie JM, Lamb D. Effects of age and smoking on the intima of muscular pulmonary arteries. J Clin Pathol 1986;39:1204-08.

10 Ferris BG, Anderson DO, Zickmantel R. Prediction values for screening tests of pulmonary function. Am Rev Respir Dis 1965;91:252-61.

11 Kory RC, Callahan R, Boren HG. The Veterans Administration-Army cooperative study of pulmonary function. I. Clinical spirometery in normal men. Am J Med 1961;30:243-58.

12 Fernie JM, McLean A, Lamb D. New method for quantitating the medial component of pulmonary arteries. Factors affecting the measurements. Arch Pathol Lab Med 1985;109:843-8.

13 Sims B. A simple method of preparing 1 to $2 \mu \mathrm{m}$ sections of large tissue blocks using glycol methacrylate. J Microscopy 1974; 101:223-7.

14 Musto L. Improved iron-hematoxylin stain for elastic fibers. Stain Technol 1981;56:185-7.

15 Fernie JM, Lamb D. New method for quantitating intimal component of pulmonary arteries. J Clin Pathol 1985;38: $1374-9$.

16 Fernie JM, Lamb D. Method for maximising measurements of muscular pulmonary arteries. J Clin Pathol 1985;38:1380-7.

17 Lamb D, McLean A, Flenley DC. A new technique for measuring alveolar surface area and the assessment of microscopic emphysema. Thorax 1986;41:716.

18 Ryan TA, Joiner BL, Ryan BF. Minitab reference manual. Boston: Duxbury Press, 1982.

19 Ryan TA, Joiner BL, Ryan BF. Minitab student handbook. Boston: Duxbury Press, 1982.

20 Smith P, Heath D. The ultrastructure of age-associated intimal fibrosis in pulmonary blood vessels. $J$ Pathol 1980;130:247-53.

21 Wright JL, Lawson L, Paré PD, et al. The structure and function of the pulmonary vasculature in mild chronic obstructive pulmonary disease. Am Rev Respir Dis 1983;128:702-7.

Requests for reprints to: Dr June M Fernie, Institute of Occupational Medicine, 8 Roxburgh Place, Edinburgh EH8 9SU, Scotland. 